\title{
MASSOTERAPIA CON BOLAS: HISTORIA Y TÉCNICA DE APLICACIÓN
}

\section{ARTÍCULO DE REVISIÓN}

BESSA, Vicente Alberto Lima ${ }^{1}$

BESSA, Maria Fátima de Sousa ${ }^{2}$

BESSA, Vicente Alberto Lima. BESSA, Maria Fátima de Sousa. Massoterapia con bolas: historia y técnica de aplicación. Revista Científica Multidisciplinar Núcleo do Conhecimento. año 04, Ed. 10, Vol. 02, págs. 05-15. Octubre de 2019. ISSN: 24480959, Enlace de acceso: https://www.nucleodoconhecimento.com.br/salud/massoterapia-con-bolas

\section{RESUMEN}

La masoterapia se ha utilizado en el logotipo de la existencia de la humanidad para diversos propósitos y hay diferentes tipos de masajes que van desde el clásico hasta el trascendental. Entre las diversas modalidades de masaje hay masaje con pelotas. Se trata de un masaje muy eficiente y poco abordado en la literatura actual, por lo que el presente estudio se realizó y se pretende investigar el origen de este masaje y describir las técnicas de aplicación. Con este fin, se llevó a cabo una investigación

1 Máster en Ciencias de la Motricidad Humana; Especialización en Fisioterapia Dermato-funcional; Especialización en Entrenamiento Deportivo y Entrenador Personal; Especialización en Gimnasia Médica; Especialización en Temas Avanzados en Fisioterapia; Especialización en portugués; Especialización en Enseñanza Innovadora de la Educación Superior; Graduado en Fisioterapia; Tecnólogo en Estética y Cosmética; Licenciatura y Licenciatura en Educación Física; Graduado en Letras; Graduado en Pedagogía.

${ }^{2}$ Máster en Ciencias de la Motricidad Humana; Especialización en Gimnasia Médica; Graduado en Fisioterapia; Licenciatura y Licenciatura en Educación Física. 
bibliográfica basada en libros y bases de datos obtenidas en Scielo y Scholar Google. Se encontró que este tipo de masaje se realizaba en la dinastía Ming y además del masaje se podían realizar ejercicios con las bolas. Básicamente hay cuatro técnicas de masaje como bolas.

Palabras clave: masaje, beneficios de masaje, masaje como pelotas.

\section{INTRODUCCIÓN}

Una de las terapias más antiguas que se ha utilizado hasta la fecha es la masoterapia y tiene diferentes fines como la disminución de las tensiones, la liberación de toxinas, promover la relajación muscular, combatir la fatiga y estimular la circulación sanguínea. (CANNECCHIA, 2019).

El masaje es una práctica común a lo largo de la historia de la humanidad y ha sido ampliamente abordado en la literatura. Hoy en día, hay varios videos de massoterapia a los que se puede acceder fácilmente a través de Internet, en Facebook, Instagram, YouTube, WhatsApp, etc. Sin embargo, es necesario señalar que no todo lo que se publica en los medios digitales es correcto y esto crea mucha confusión para los laicos y principiantes en el mundo de la estética. Por lo tanto, es importante desarrollar estudios que permitan la correcta divulgación de las diversas técnicas de la masoterapia y sus beneficios reales.

Se sabe que hay diferentes tipos de masoterapia, tales como: sueco, tailandés, hawaiano, tántrico, indio, etc., pero una de las técnicas menos descritas es el masaje con bolas, o simplemente masaje con pelotas. Es una técnica de masaje que se aplica a los tejidos blandos y ejerce tres efectos básicos: mecánico, fisiológico y psicológico. Su aplicación sigue principios similares a la masoterapia sueca, sin embargo, el uso de bolas para masajear la región corporal.

Se sabe que hay una falta de literatura científica sobre el uso del masaje de bolas, por lo que el presente estudio se llevó a cabo y tenía como objetivo investigar el origen de este masaje y describir las técnicas de aplicación. Para ello, se llevó a cabo una 
investigación bibliográfica basada en libros y bases de datos obtenidas en Scielo y Scholar Google, que tuvo como descriptores: masaje, beneficios del masaje, masaje como pelotas.

\section{REVISIÓN DE LA LITERATURA}

\subsection{HISTORIA DEL MASAJE}

Hay registros históricos que demuestran que incluso las primeras civilizaciones silvestres, además de las civilizadas, ya practicaban algún tipo de masaje, especialmente la fricción (WOOD y BECKER, 2008). Era una práctica común en las antiguas civilizaciones india, china, japonesa, griega y romana. Se sabe que una de las referencias más antiguas aparece en Nei Ching, que es un texto médico chino que fue escrito en un período anterior al 1500 a. C. Más tarde, los escritos fueron encontrados sobre el masaje por los médicos hipócrates en el siglo V a. C. y Avicenna y Ambrose Stop, respectivamente, en los siglos X y XVI. (CASSAR, 2001).

Sin embargo, los egipcios ya aplicaron el masaje con fines terapéuticos a más de 4000 a. C. Y en la India, el masaje buscó una visión holística para equilibrar el cuerpo, la mente y el espíritu y ser una de las recomendaciones y enseñanzas. Se sabe que la descripción del masaje se encuentra en los libros Ayur Veda que fueron escritos alrededor de 1800 a. C. Sin embargo, se sabe que casi todas las principales culturas del mundo han propuesto en detalle las indicaciones y beneficios del masaje que comúnmente se combinó con otros tipos de tratamiento tradicional, especialmente los tratamientos de baño. (SILVA, 2016).

Es necesario destacar que Hipócrates (480 a. C.) Ilamó el masaje de la anatripsis, cuyo significado es "frotar presionando el tejido", más tarde el término fue traducido a la palabra latina frictio, que significa "fricción" o "rubbing". Se sabe que este término predominó durante mucho tiempo y fue utilizado en los Estados Unidos hasta 1870. En la India, el masaje se llamaba shampoing; en China, Cong-Fou; en Japón, Ambouk (CASSAR, 2001). 
A su vez, Hipócrates (460-370 a. C.) también utilizó el masaje como tratamiento, porque creía que el cuerpo es capaz de auto-curarse si se estimula adecuadamente. Asclepíades de Bitínia fue otro médico griego que utilizó masajes, dietas y ejercicios para tratar enfermedades. Además, no es notorio saber que las primitivas civilizaciones australiana, egipcia, rusa, ucraniana, pacífico y norte y sudamericano utilizaron el masaje a través de movimientos de fricción con aceites y aguas como una manera de expulsar demonios y los espíritus que generaron enfermedades en las personas y así purificaron el cuerpo de los enfermos. Por lo tanto, varias personas han utilizado y recomendado el masaje para beneficiar la salud de los seres humanos. (BERTOJA e TOKARS, 2018).

Sin embargo, el masaje no siempre ha sido bien considerado, con el auge del cristianismo en la Edad Media (el período histórico que va desde el siglo $\mathrm{V}$ hasta el siglo XV), el culto del cuerpo llegó a ser considerado un pecado. Por lo tanto, el cuidado de la higiene ya no se toma y por lo tanto el masaje estaba prohibido en civilizaciones crestadas. (BRAUN y SIMONSON, 2007). En Europa, Ia Iglesia Católica consideraba el masaje un pecado y su asociación con hierbas medicinales era considerada como un acto de brujería. (RAMOS, 2017).

Con el final de la Edad Media y el surgimiento del Renacimiento, el masaje fue descubierto y aplicado de nuevo y varios autores contribuyeron a este hecho. Sin embargo, fue entre 1776 y 1839 que Pehr Henrik Ling revolucionó la práctica de ejercicios y masajes. Creó las terminologías y la técnica del masaje sueco que también se conoce como masaje clásico o curación por el movimiento sueco. Su técnica fue popularizada inicialmente en Europa y Rusia y más tarde globalizada (WOOD y BECKER, 2008).

También fue Hipócrates quien describió los beneficios del masaje asociado con las propiedades químicas de los aceites utilizados (FRITZ, 2002). Por lo tanto, se puede ver que no sólo el masaje podría traer beneficios, sino también la propiedad química de ciertos aceites vegetales y esenciales. 
La palabra masaje se origina a partir de la masa griega que significa "amasado" que significa tocar, manejar, apretar (FRITZ, 2002). Sin embargo, el término masoterapia es actualmente preferible, ya que la palabra terapia indica el uso terapéutico del masaje. Hoy en día, existen varias técnicas de masaje entre ellas: relajante, deportiva, terapéutica, modelaje, Masaje Rápido, reflexológico, tántrico, etc. Así como han surgido varios tipos de equipos que ayudan al terapeuta a aplicar el masaje, entre ellos se encuentran las bolas de baoding o bolas de salud.

Las bolas de baoding (Figura 1) son de origen chino y su denominación proviene de la ciudad del baoding, ubicada en la provincia de Hebei en la República Popular China. Son artefactos utilizados para ejercitar las manos y proporcionar relajación, disminuyendo el estrés. Tradicionalmente, se componen de un par de bolas de hierro de pequeño tamaño, que se almacenan en una pequeña caja rectangular. Estas bolas se originan en la dinastía Ming (1368-1644 d.C.) y fueron hechas por un artesano de armas guiado por un sueño celestial. Creó dos bolas de hierro basadas en el concepto yin/yang: una que representaba el rugido del dragón y la otra la esquina del Fénix.

Al principio, el Emperador de China estaba encantado con los beneficios terapéuticos proporcionados por las bolas y las convirtió en un instrumento que sólo podía ser utilizado por la familia real. Más tarde, las bolas de hierro se hicieron populares y llegaron al mundo. Inicialmente, se utilizaron para mejorar la condición física y entrenar el temperamento (disminuir la ansiedad, calmarse) propósito para el que todavía se utilizan hoy en día. Son un aparato para relajar músculos y articulaciones y para la defensa en la práctica de artes marciales.

Hoy en día, las bolas de baoding están hechas de múltiples tipos de materiales, pero siguen siendo ligeras de llevar. A menudo son huecos y están hechos de acero cromado y contienen guizos en su interior. Los guizos proporcionan sonidos que pueden sonar como campanas relajantes que responden a la naturaleza y la influencia de los cinco dedos, ejercitando así los músculos y activar la circulación sanguínea. 


\section{(-) NU) NUCLEO DO \\ CONIECIMENIO https://www.nucleodoconhecimento.com.br}

Figura 1: Bolas baoding.

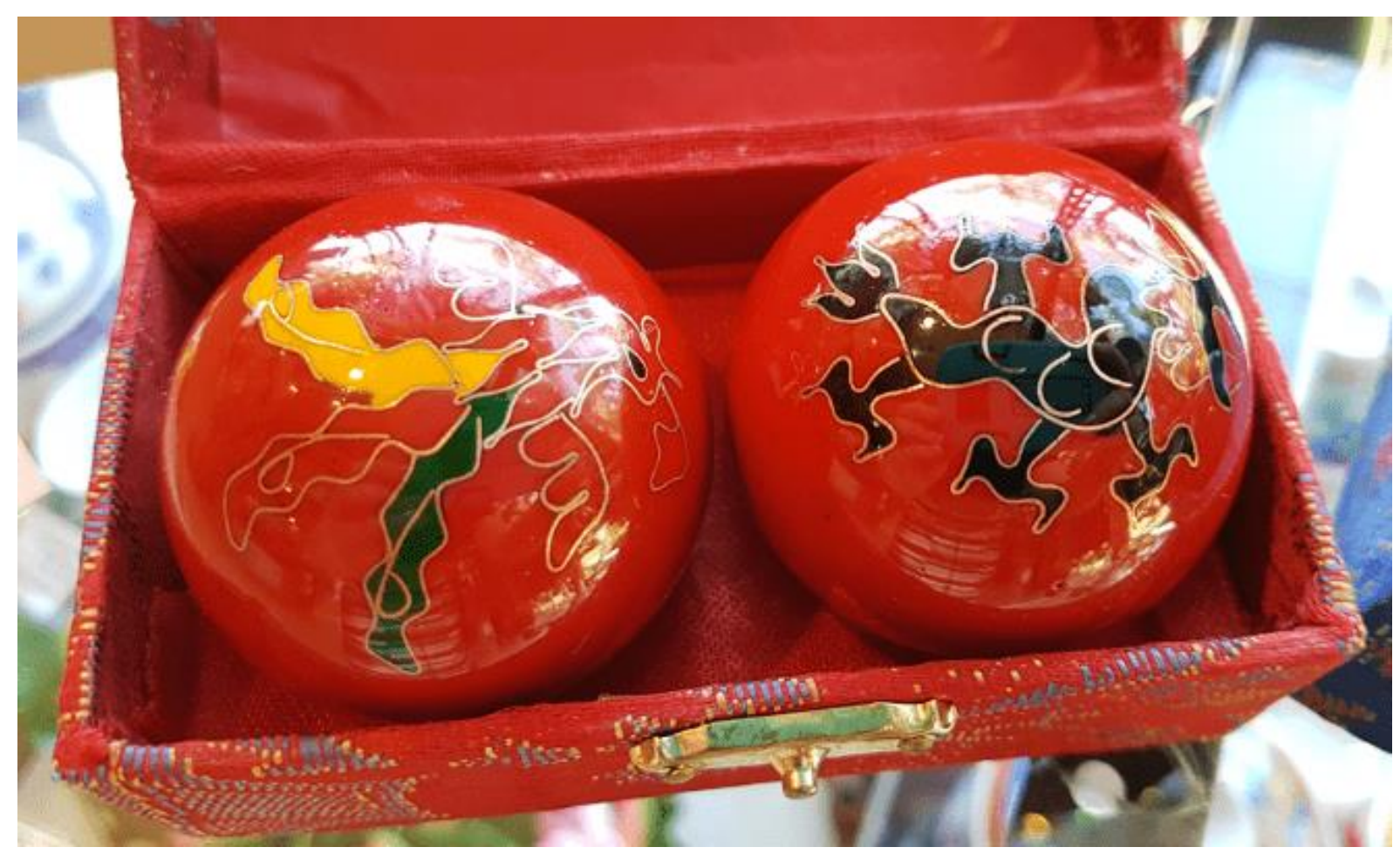

Fonte: Os autores

Con el desarrollo de nuevos materiales y la evolución de la técnica, las bolas comenzaron a ser producidas con materiales magnéticos, madera, silicona y metal, caucho, silicona, etc. (Figura 2)

Figura 2: Diferentes tipos de bolas.
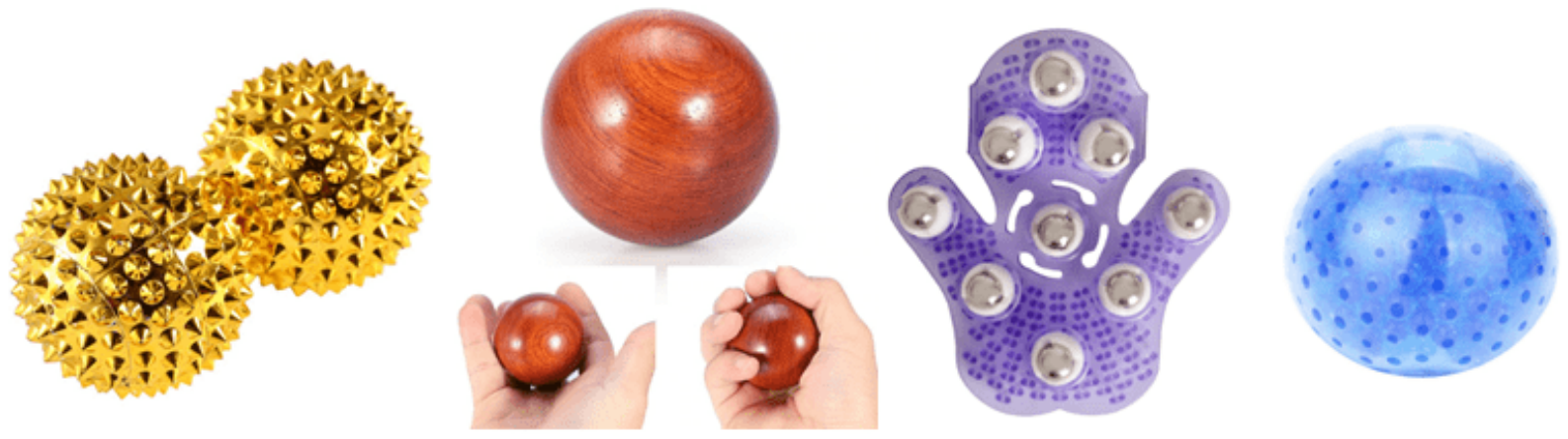

Fonte: Os autores 
Cuando las bolas de hierro aparecieron, eran únicas para masajear sus manos. La persona se automasajeó girando las bolas entre sus dedos. Esta técnica todavía es ampliamente utilizada, pero es posible masajear cualquier parte del cuerpo con la ayuda del terapeuta o incluso varias partes del cuerpo a través del auto-masaje. (Figura 3)

Figura 3: Automasaje con bola.
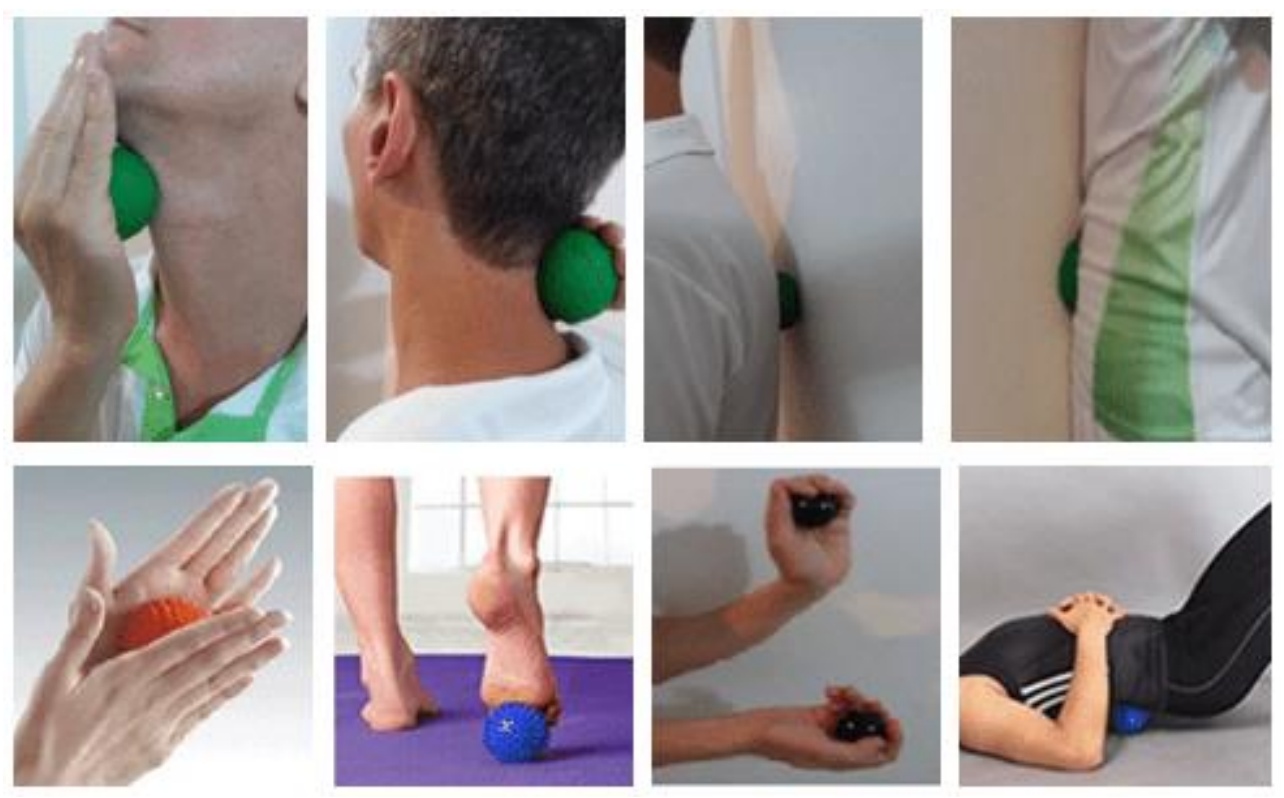

Fonte: Os autores

\subsection{MASAJE DE PELOTA: BENEFICIOS}

El masaje de bolas (masaje de bolas) se aplica a los tejidos blandos y ejerce tres efectos básicos: mecánico, fisiológico y psicológico. Los principales efectos del masaje son mecánicos, pero generan efectos fisiológicos y psicológicos.

El masaje es una técnica que promueve la manipulación en tejidos blandos y como cualquier tipo de masaje relajante, permite la disminución de las tensiones musculares, además de estimular la producción de serotonina e histamina que tienen acción vasodilatadora, aumentando sangre y la entrada linfática. El masaje puede activar los rmoreceptores y aumentar la permeabilidad de la membrana celular, esto 
permite la absorción de nutrientes y consecuentemente una mejor nutrición celular, oxigenación e hidratación (CLAY, 2008).

Psicológicamente, el masaje de pelota es capaz de proporcionar relajación muscular y mental, causando un estado propenso a dormir. Se sabe que el masaje estimula la liberación de hormonas endorfinas y serotonina que son responsables de la sensación de placer. (PEREIRA, 2013). Hormonas de endorfinas y serotonina permiten la relajación y al mismo tiempo son los responsables del sueño profundo, que se designa con sueño REM. Además, el masaje reduce el cortisol que es uno de los responsables del insomnio/estrés, por lo que una persona que recibe el masaje tendrá menos cortisol en el torrente sanguíneo, lo que provocará una mejora en su calidad del sueño y disminución de la ansiedad y el estrés.

Los movimientos de estiramiento, compresión, tracción y fricción que se realizan en el masaje de bolas ejercen fuerzas mecánicas evidentes sobre los tejidos. Estas fuerzas mecánicas ejercen efectos movilizadores de ablandamiento y estiramiento sobre la piel, tejido subcutáneo, vísceras y músculos.

El efecto mecánico se refiere a las influencias directas que el masaje juega en los tejidos blandos que se masajean (CASSAR, 2001). Proporciona efectos fisiológicos en los sistemas muscular, nervioso, circulatorio y digestivo. Masajear con bolas cuando la eliminación lenta de los músculos estimula el reflejo del tendón que reduce la tensión muscular y resulta en la relajación muscular. Con la relajación muscular esquelética y las maniobras deslizantes realizadas con bolas es posible ejercer suficiente presión para desplazar los líquidos en la dirección del flujo circulatorio venoso o linfático. Si las maniobras son vigorosas, pueden resultar en aumentos significativos en el flujo sanguíneo debido a los fenómenos de vasodilatación y capilarización. Estos efectos circulatorios impulsan los intercambios entre los medios celulares y de la sangre, mejoran el oxígeno y el insumo nutricional, ayudan en la eliminación de residuos del metabolismo y el dióxido de carbono. Las maniobras con mayor presión suable, rítmicas y aplicadas hacia los caminos de los vasos linfáticos superficiales permiten acelerar el flujo de retorno linfático, siendo útiles en casos de edema para ayudar en la reabsorción. 
Los principales efectos mecánicos producidos por el masaje son: la movilización de sangre venosa, linfa, edema y hematoma, contenido intestinal, moco, fibras musculares y masa, tendones, piel y tejido subcutáneo, adherencias y tejido cicatricial (Gobierno del Estado del Ceará, 2010).

También destacamos los efectos fisiológicos del masaje de bolas en el sistema digestivo que mejoran el tránsito intestinal. El masaje estimula la peristalsis para promover la evacuación de pisos y heces del intestino grueso, facilitando la función excretoria en casos de estreñimiento intestinal.

Sin duda la reducción del dolor al aplicar el masaje se obtiene por diferentes mecanismos, entre la disminución del espasmo muscular y el edema. Por lo tanto, la mejora de la circulación de retorno absorbe el edema y con él los metabólicos celulares. También se reduce mediante la activación de receptores de la piel que inhiben el dolor por el mecanismo de la puerta (STARKEY, 2017).

La relajación muscular y la mejora de la circulación ya contribuyen a disminuir las algias musculoesqueléticas. Sin embargo, el masaje de bolas reduce el dolor porque obedece a los fenómenos de la teoría de inundaciones. Esta teoría nos permite entender que hay diferentes tipos de fibras nerviosas y cada uno tiene una velocidad de conducción de impulso nervioso y una función. En este caso, la fibra nerviosa del dolor es más lenta que la fibra nerviosa de tacto y presión. Por lo tanto, cuando una persona está sintiendo un dolor muscular y se masajea, los impulsos nerviosos de tacto y presión llegan primero en la médula espinal e inhiben las vías nerviosas del dolor que llevarían a la información del dolor al tálamo (sitio del cerebro que permite sentir la de la r).

El efecto del masaje en el control del dolor es tan importante que se utiliza como cuidados paliativos en pacientes con cáncer en estadio avanzado. Un hecho que se encuentra en la declaración de florentino (2012, n.p.) que informa que "el masaje es una técnica utilizada como terapia complementaria en pacientes con cáncer, con el objetivo de proporcionar alivio del dolor." 
Cabe destacar que para que se produzcan efectos inhibitorios, es necesario que las maniobras de masaje con bolas se realicen de forma constante, lenta y suave, de modo que el alojamiento se produzca aumentando el umbral de percepción del nuevo estímulo.

El masaje de bolas ayuda en la renovación de las células epidérmicas y permite que las glándulas sebáceas estén claras y funcionen mejor. Y debido a los fenómenos vasodilatadores y la capilarización, la piel se nutre y oxigena, además de facilitar la permeación de algunos activos cosméticos.

La masoterapia puede ejercer una influencia en el sistema inmunitario, ya que actúa sobre las capas de la piel que responde positivamente. (CARVALHO e ALMEIDA, 2018).

\subsection{MASAJE DE BOLA: ORIENTACIONES, INDICACIONES Y CONTRAINDICACIONES}

Antes de aplicar el masaje con bolas es necesario que el terapeuta haga una evaluación (anamnesis) del cliente. La evaluación proporcionará información útil para elegir si la persona a masajear, y permite seleccionar las maniobras prioritarias a aplicar. Durante la evaluación, si el cliente presenta alguna contraindicación relativa, se le debe indicar que consulte a otro profesional de la salud y sólo puede ser masajeado si tiene una autorización por escrito del médico o fisioterapeuta.

Los principales datos que deben estar presentes en el formulario de evaluación son: datos de identificación (nombre completo, dirección, número de teléfono, fecha de nacimiento, estado civil y profesión), datos sobre el estado de salud (ya sea que la persona esté sana o tenga alguna enfermedad: diabetes, hipertensión o hipotensión, enfermedades del corazón, cáncer, migraña, epilepsia, estreñimiento, dismenorrea, cistitis, alergias, insomnio, depresión, etc.) y es necesario saber si la persona está embarazada o amamantando. Otra información que puede contener en el formulario de evaluación es sobre la práctica del ejercicio físico, la alimentación, el consumo de bebidas alcohólicas, el tabaco y los medicamentos en uso. 
La aplicación de la masaterapia de pelota presta atención a las mismas contraindicaciones de cualquier aplicación de masaje y pueden ser absolutas, es decir, el masaje no se puede aplicar al cliente; o relativo, es decir, es posible aplicar masaje, pero se debe tener cuidado o algunas áreas no se pueden masajear.

Las principales contraindicaciones absolutas son trombosis o daño vascular inestable, estado febril, presencia de infección, gangrena, enfermedad renal, enfermedad cardíaca avanzada, dolor de cabeza intenso, cambios incontrolados en la presión arterial por medicación, Intoxicación. Las contraindicaciones relativas son: fracturas (antes de solidificarse), quemaduras recientes, heridas abiertas. (VERSAGI, 2015). Otras contraindicaciones relativas son: cáncer, enfermedad mental, descalcificaciones y embarazo.

Las principales indicaciones son: alivio del estrés, estreñimiento, migraña, recuperación de la persona en casos de lesiones traumáticas (esguince, hematomas) después de la liberación médica, reducir las tensiones musculares y tendinosas, mialgias por esfuerzo, prevención de STDs, drenaje de edema venoso y linfático, adyuvante en el tratamiento de estrías, lipodistrofia localizada, eedemaculopatía fibrosclerótica, insomnio, ansiedad, etc.

\subsection{MASAJE DE PELOTA: TECNICACIONES}

Se deben seguir algunas reglas básicas para aplicar el masaje, tales como: tanto el masajista como el cliente deben sentirse cómodos durante la sesión; el contacto con el cliente no debe eliminarse repentinamente; masaje debe interrumpirse en regiones donde el paciente siente dolor; nunca presione ni masajee directamente a la columna vertebral. (ELLSWORTH, 2012).

Las maniobras de masaje de bolas deben respetar los principios de dirección, presión, velocidad, ritmo y duración de acuerdo con los objetivos deseados.

La dirección dependerá del efecto deseado, por lo que se puede realizar en la dirección de circulación que se desea potenciar o en la dirección de las fibras 
musculares a masajear. En cuanto al flujo arterial, las maniobras deben ser centrífugas o casi distales para masajear las extremidades, tronco y cuello y centrípeta o proximal para masajear la cabeza. Si la dirección del flujo es venosa, las maniobras deben ser centrípetas o esta-proximales para masajear las extremidades, el tronco y el cuello y las centrífugas o casi distales para masajear la cabeza. Si se apunta al drenaje linfático es necesario seguir la dirección del flujo de los vasos linfáticos y mantener la secuencia de drenaje propuesta por José María Pereira de Godoy y María de Fátima Guerreiro Godoy.

En cuanto a la presión a ejercer, debe ser cómodo y agradable cuando se busca la relajación muscular y la reducción del dolor. Cabe destacar que es necesario que los clientes se ajusten de los comentarios de los clientes. Hay más personas musculosas u obesas donde la presión tenderá a ser ligeramente mayor en comparación con magros, ancianos o niños. Si usted apunta al drenaje linfático, la presión debe estar entre 30 y $40 \mathrm{mmHg}$.

La velocidad y el ritmo también varían dependiendo de la necesidad. Las maniobras de relajación y drenaje deben ser lentas, constantes y bien rítmicas. Para la dinamización circulatoria arterial, tratamiento de estriación, lipodistrofia localizada, fibroedemageloide debe ser más rápido. Es bueno recordar que los movimientos realizados lentamente tienden a ser relajantes, mientras que lo contrario, más estimulante.

El masaje dura de 5 a 20 minutos cuando se aplica en una sola región, excepto si el objetivo es el drenaje linfático, en este caso durará de 30 a 40 min. Cuando se aplica de forma sistémica, es decir, en todo el cuerpo, con el objetivo de la relajación muscular y la disminución de las tensiones emocionales, durará de 45 a 90 min.

Cabe señalar que el tiempo dependerá en gran medida del objetivo a alcanzar, y del tamaño de la zona del cuerpo, ya que se necesita menos tiempo para tratar a una persona relativamente pequeña en comparación con una persona grande. En personas muy jóvenes y muy mayores, la duración del masaje debe reducirse, ya que el arco reflejo es más sensible y el efecto integral se logra más rápido. 
El masaje de pelota aplicado por el terapeuta se divide en cuatro maniobras básicas y cada maniobra tiene sus variaciones. La maniobra que inicia y termina el servicio es la del deslizamiento, que consiste en deslizarse hacia o con las bolas en la superficie corporal del cliente siempre en respuesta al flujo circulatorio deseado o la dirección de las fibras musculares o la sensación de peristalsis (Figuras 4 a 11).

Figura 4: Técnica de deslizamiento longitudinal simétrica en Mmli.
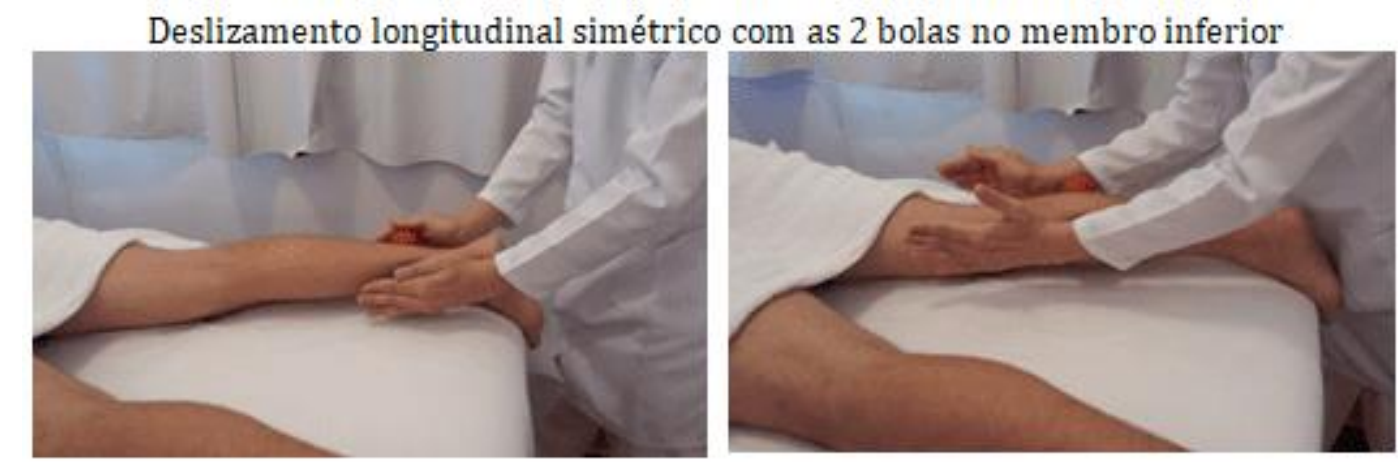

Fonte: Os autores

Figura 5: Técnica de deslizamiento longitudinal asimétrico en el tronco.

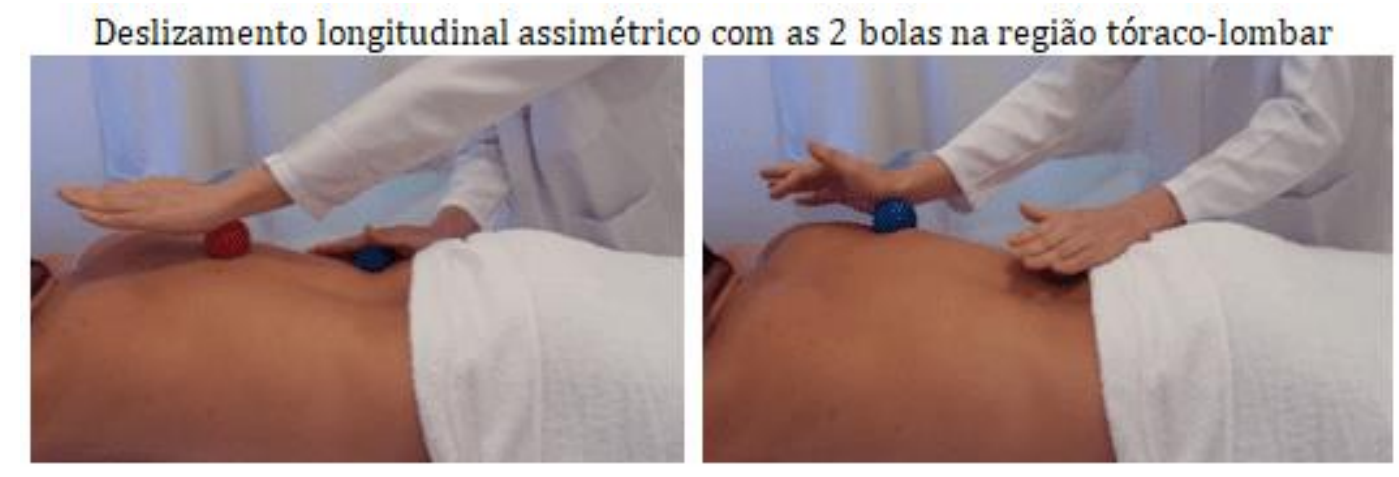

Fonte: Os autores 
Figura 6: Técnica de deslizamiento cruzado.

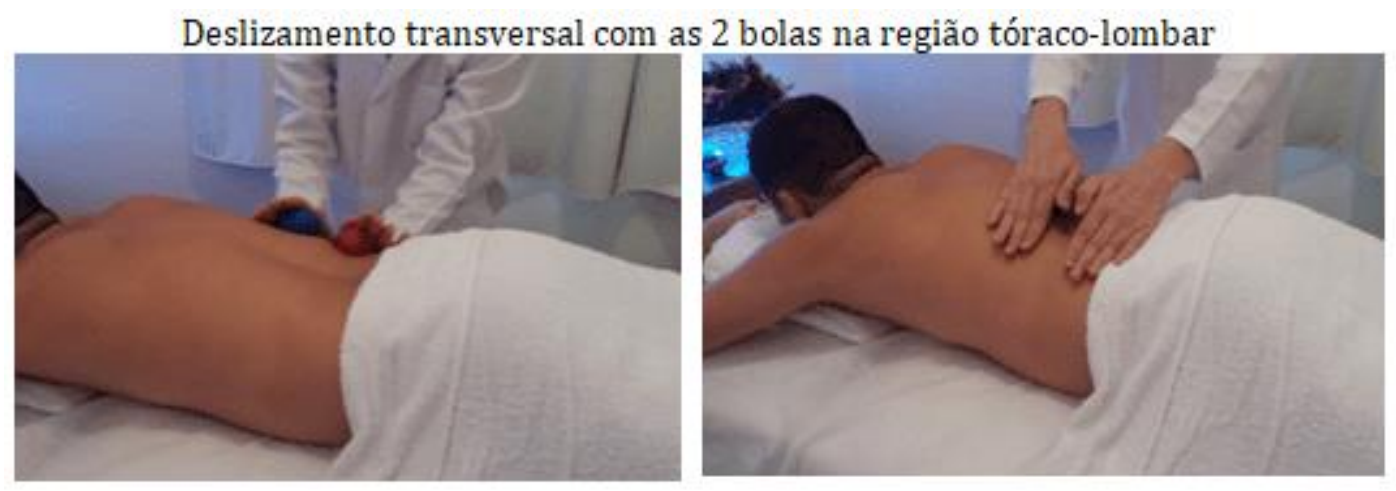

Fonte: Os autores

Figura 7: Técnica de deslizamiento longitudinal simétrica en el tronco.

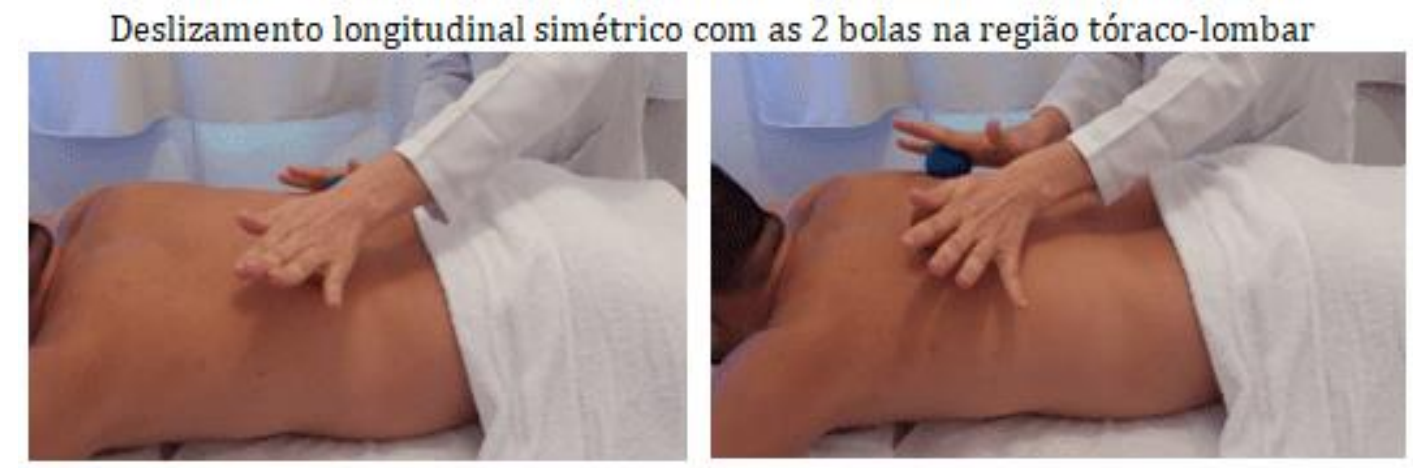

Fonte: Os autores

Figura 8: Técnica de deslizamiento circular.

Deslizamento circular com uma bola na região abdominal no sentido do peristaltismo. A manobra pode ser executada com uma ou duas mãos.

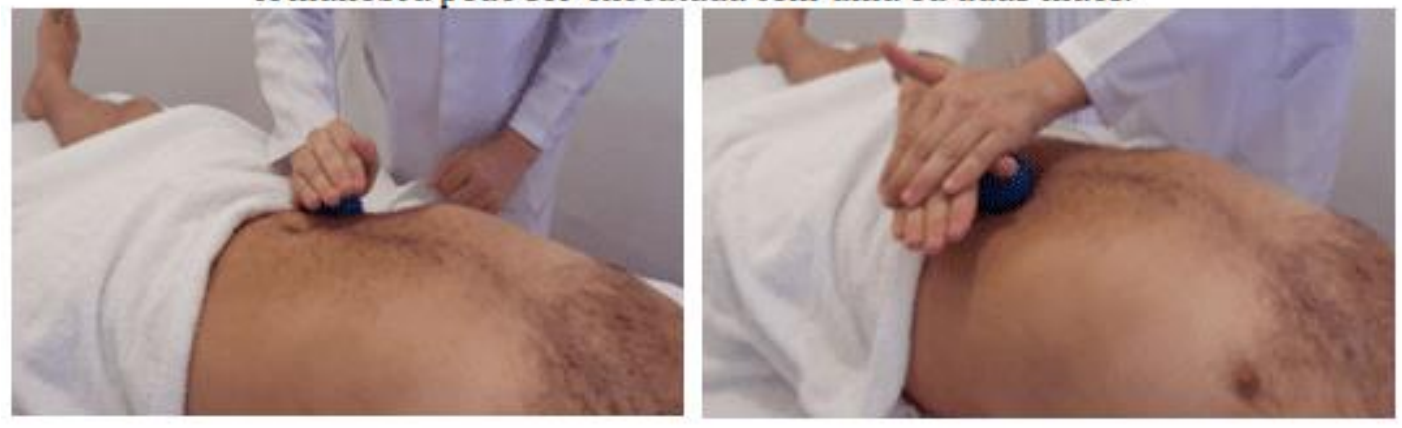

Fonte: Os autores

RC: 41886

Disponível em: https://www.nucleodoconhecimento.com.br/salud/massoterapia-con-bolas 
Figura 9: Técnica de deslizamiento longitudinal simétrica en el antebrazo.

Deslizamento longitudinal simétrico com as 2 bolas na mão e no antebraço
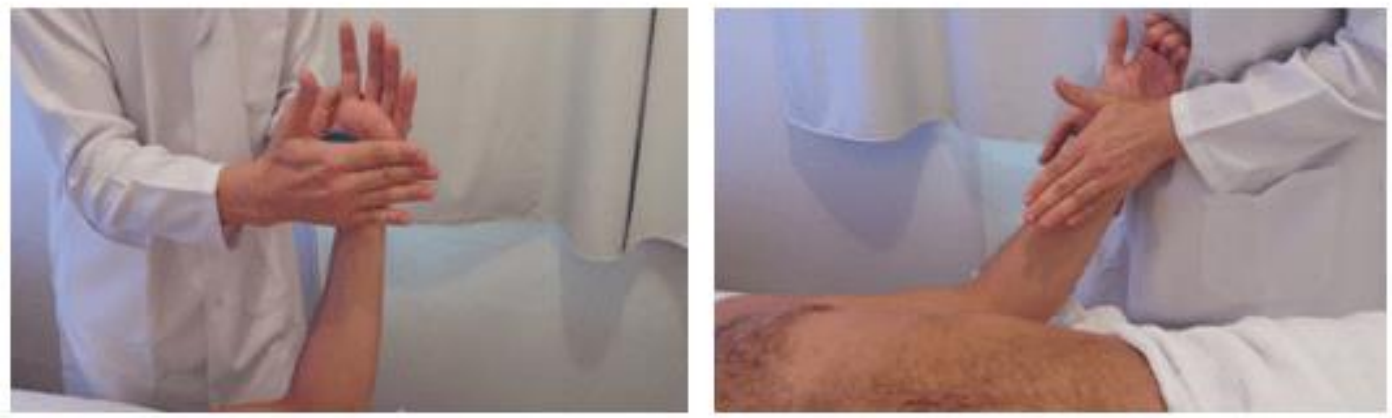

Fonte: Os autores

Figura 10: Técnica de deslizamiento longitudinal simétrica en el brazo.

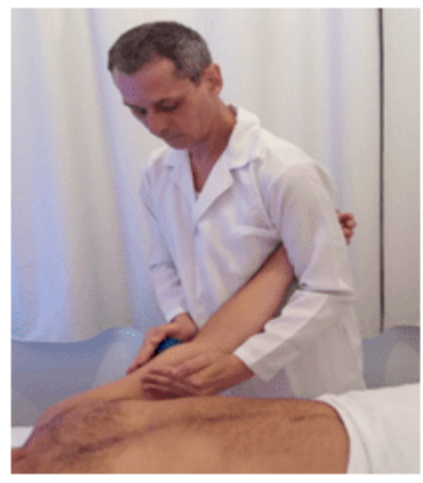

Deslizamento longitudinal simétrico com as 2 bolas no braço. Observe que o terapeuta sustenta 0 membro superior fixando-o entre o tronco e o braço. É fundamental que $o$ cliente não sustente $\circ$ membro.

Fonte: Os autores

Figura 11: Técnica de deslizamiento diagonal.

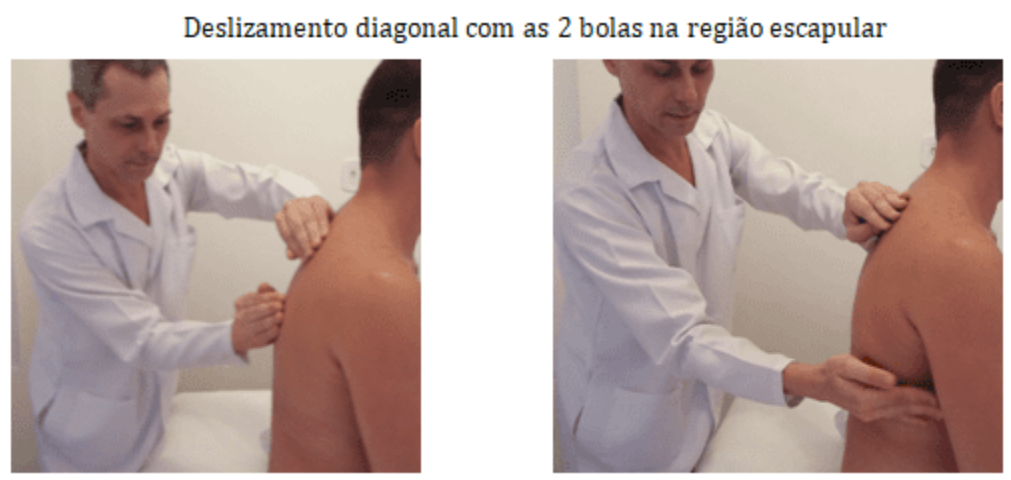

Fonte: Os autores

RC: 41886

Disponível em: https://www.nucleodoconhecimento.com.br/salud/massoterapia-con-bolas 
La segunda maniobra es compresión fija o compresión y arrastre. La primera es mantener la región siendo comprimida por la pelota durante 10 a 15 segundos o durante toda la sesión. El segundo, consiste en comprimir la bola contra el cuerpo y arrastrarla a movimientos circulares (Figuras 12 y 13).

Figura 12: Técnica de compresión en el pie.

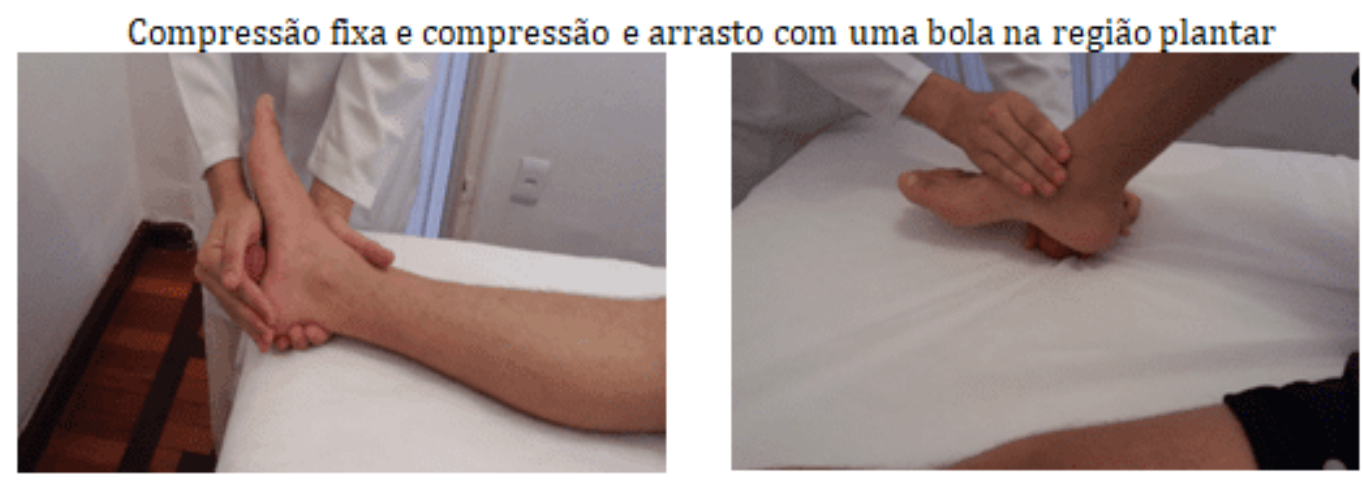

Fonte: Os autores

Figura 13: Técnica de compresión en la columna vertebral.

Compressão fixa com as 2 bolas na região paravertebral cervical e lombar
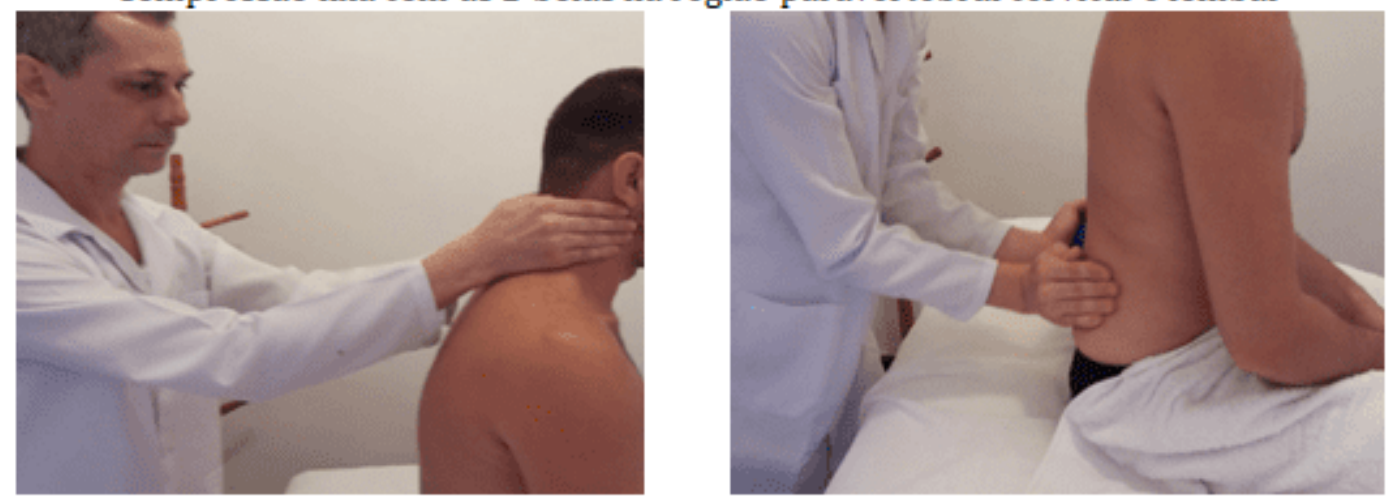

Fonte: Os autores

La tercera maniobra es amasar y en este caso siempre se utilizan dos bolas. El terapeuta amasa el tejido blando entre las bolas con buena presión o presión fuerte, pero no incómodo. El cliente no puede reportar dolor o molestia en ninguna hipótesis (Figura 14). 
Figura 14: Técnica de amasado.

Amassamento de trapézio e da loja posterior de perna
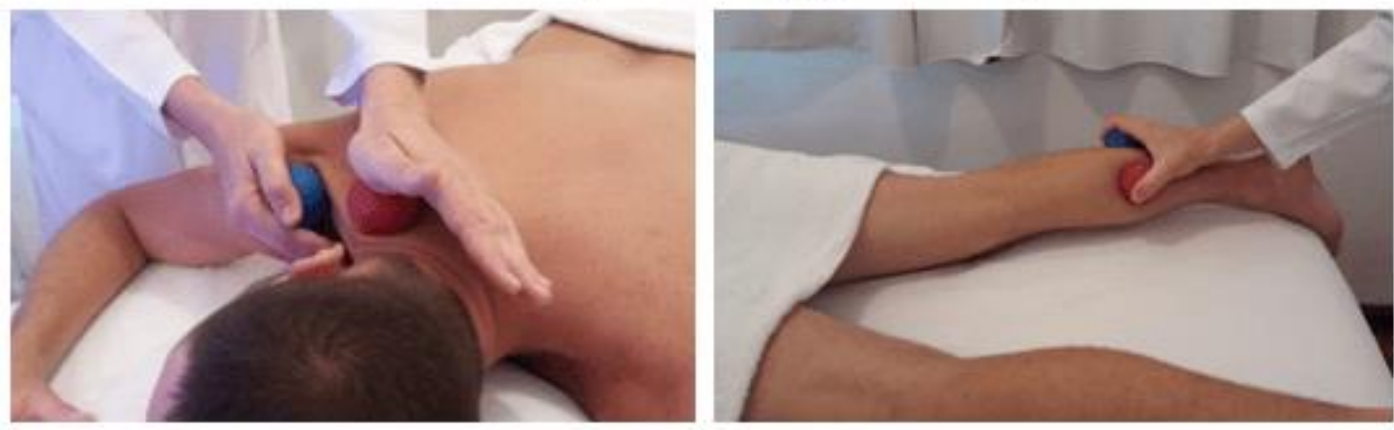

Fonte: Os autores

La cuarta maniobra básica es la fricción y en este caso, se utiliza generalmente en regiones pequeñas y con una sola bola. Esta maniobra es una especie de deslizamiento profundo, realizado vigorosa y rápidamente, con el fin de reducir los nódulos de tensión muscular, deshacer coágulos, aumentar la microcirculación local. Provoca un gran calentamiento de la región masajeada y se recomienda en casos de estrías y lipodistrofia localizada. Las maniobras tienen como objetivo calentar la región y se realizan con la bola que circula entre la palma y la superficie corporal del cliente (Figura 15).

Figura 15: Técnica de fricción.

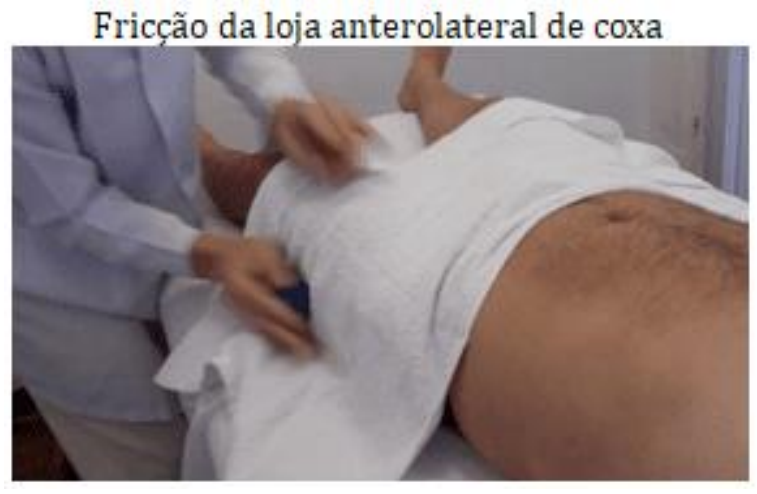

Fonte: Os autores 
Hay variaciones de cada una de las maniobras básicas, además de la Técnica de Automasaje con bolas, que la persona aplica el masaje en él (Figura 16).

Figura 16: Técnica de automasaje.

\section{Self Ball Massage}

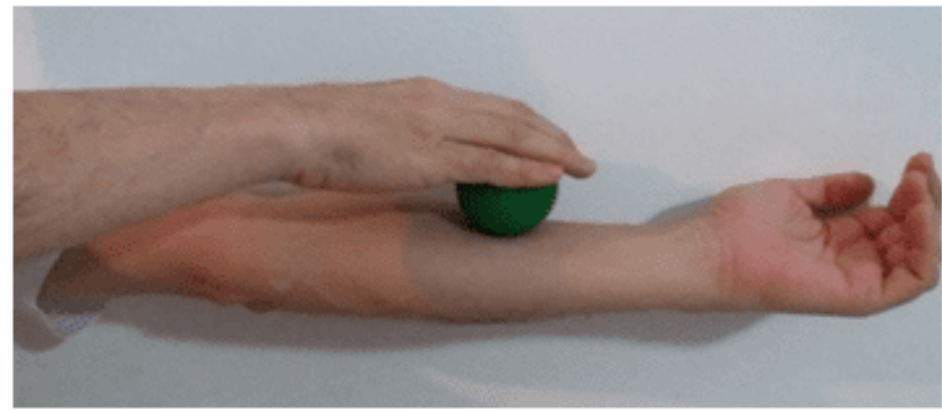

Fonte: Os autores

\section{CONCLUSIÓN}

Los primeros registros históricos de la masoterapia se remontan a 1800 a. C. y se encuentra en los libros Ayur Veda, pero se sabe que los egipcios utilizaron el masaje con fines terapéuticos durante más de 4000 a. C. E fue en la dinastía Ming (1368-1644 d.C.) que un artesano de armas creó dos bolas de hierro basadas en el concepto yin/yang. Comenzaron a ser empleados para proporcionar efectos terapéuticos y para mejorar la condición física y entrenar el temperamento (disminuir la ansiedad, calmarse).

Hoy en día todavía se utilizan bolas de hierro, pero otros materiales surgieron con madera, silicona, caucho y varios otros. Todas estas bolas, independientemente del material, sirven para masajear y hacer ejercicio y pueden proporcionar beneficios orgánicos y psicológicos ya reconocidos en la masoterapia. Se puede ver que el masaje de bolas aplicado por el terapeuta se divide en 4 maniobras básicas, sin embargo cada maniobra tiene sus variaciones. 


\section{REFERENCIAS}

BERTOJA, Vanessa Gomes Bertoja; TOKARS, Eunice. Os benefícios da massagem relaxante.

em:

https://www.librarybus.com/view?t=0s+benef\%C3\%ADcios+da+massagem+relaxant e+-+TCC+On-line+-

+Tuiuti\&u=http\%3A\%2F\%2Ftcconline.utp.br\%2Fmedia\%2Ftcc\%2F2017\%2F05\%2F OS-BENEFICIOS-DA-MASSAGEM-RELAXANTE.pdf. Acesso em: 10 jan.2018.

BRAUN, Mary Beth; SIMONSON, Stephanie. Massoterapia. São Paulo: Manole, 2007.

CANNECCHIA, Marcela Cleto. Benefícios da massagem relaxante para o homem da atualidade. Pesquisa e Ação. Mogi das Cruzes, SP. v.5, n.1, p. 46-49. Jun. 2019. Disponível em: https://revistas.brazcubas.br/index.php/pesquisa/article/view/574/703. Acesso em: 05 ago. 2019.

CARVALHO, Rosemeire de Jesus; ALMEIDA, Maria Antonieta Pereira Tigre. Efeitos da Massoterapia sobre o Sistema Imunológico. Id on Line Rev. Mult. Psic. v.12, n. 40. p.353-366, 2018

CASSAR, Mario-Paul. Manual de Massagem Terapêutica: um guia completo de massoterapia para o estudante e para o terapeuta. São Paulo: Manole, 2001.

CLAY, James. H.; POUNDS, David. M. Massoterapia Clínica: integrando anatomia e tratamento. São Paulo: Manole, 2008.

ELLSWORTH, Abigail. Massagem: anatomia ilustrada, guia completo de técnicas básicas de massagem. Barueri, São Paulo: Manole, 2012.

Florentino, Danielle de M. A fisioterapia no alívio da dor: uma visão reabilitadora em cuidados paliativos. Brazilian Journal of Health and Biomedical Sciences. Rio de Janeiro; Revista do Hospital Universitário Pedro Ernesto. v.11, n.2, abr/jun, 2012. 
FRITZ, Sandy. Fundamentos da Massagem Terapêutica. 2.ed. São Paulo: Manole, 2002.

GOVERNO DO ESTADO DO CEARÁ. Técnico em Massoterapia: técnicas clássicas e modernas de massoterapia. Escola Estadual de Educação Profissional - Ensino Médio Integrado à Educação Profissional - Curso Técnico em Massoterapia. Fortaleza Ceará, 2010.

PEREIRA, Maria de Fátima Lima. Recursos Técnicos em Estética. Vol. I. Série Curso de Estética. São Paulo. Difusão Editora. 2013.

RAMOS, Andréa Rosa. Técnicas de massagem corporal. Londrina: Editora e Distribuidora Educacional S.A, 2017

SILVA, Carina Geremias dos Santos. Massoterapia Mãos de Anjo. Plano de Negócios. PG, Gravataí, v. 2, n. 2, 2016. Disponível em: http://revista.faqi.edu.br/index.php/PN/article/view/259/277. Acesso em: 02 ago 2019.

STRARKEY, Chad. Recursos Terapêuticos em Fisioterapia. 4 ed. São Paulo: Manole, 2017.

VERSAGI, Charlotte Michael. Protocolos Terapêuticos de Massoterapia: técnicas passo a passo para diversas condições clínicas. Barueri, São Paulo: Manole, 2012.

WOOD, E. C; BECKER, P. D. Técnicas de Massagem de Beard. 5. ed. Rio de Janeiro: Elsevier, 2008.

Enviado: Agosto, 2019.

Aprobado: Octubre, 2019. 